\title{
PERMANÊNCIA ESCOLAR, MEMÓRIA E AUTORIA: Uma proposta de formação continuada da UENF para docentes de Educação de Jovens e Adultos ${ }^{(*)}$
}

\author{
Gerson Tavares Carmo ${ }^{(* *)}$
}

\section{A TÍTULO DE INTRODUÇÃO: ORIGEM DA PROPOSTA DE FORMAÇÃO CONTINUADA}

A operacionalização de uma proposta de pesquisa-ação na extensão universitária, com foco na formação de professores, insere-se no conjunto de ações inéditas assumidas pela UENF, pontualmente a partir do ano de 2010, com o projeto de pesquisa Diagnóstico da EJA. O referido projeto foi desenvolvido em alguns municípios da região Norte Noroeste Fluminense do estado do Rio de Janeiro, a saber: Campos dos Goytacazes, Cardoso Moreira, Bom Jesus do Itabapoana, Italva, Itaperuna, Laje de Muriaé, Natividade, Porciúncula e Varre-Saí. Por meio dele, realizaram-se ações de coleta e análise de dados referentes a informações sobre a EJA. A fase de análises e reflexões do material coletado na cidade de Itaperuna, em especial, fez emergir alguns questionamentos como: o que influencia a permanência dos alunos nas instituições educacionais? Qual a relação dessa permanência na qualidade da educação no município?

Debruçando-se sobre essas questões e nesse território geográfico pretendeu-se avançar com uma proposta de pesquisa-ação e extensão universitária. Além de buscar cumprir os objetivos pontuais da extensão na universidade (como parte do tripé dessas instituições, unida ao ensino e à pesquisa), a intenção foi constituir um ambiente de discussão local com vista ao fortalecimento dos vínculos entre pesquisadores, gestores, pedagogos e docentes por uma EJA de qualidade.

A atividade proposta teve como referência de extensão e pesquisa o vínculo do seu coordenador com projetos financiados pela Faperj, tanto para a UENF quanto para a UERJ, parceira em diversos momentos de trabalho, nos anos de 2010 e 2012.

\footnotetext{
${ }^{(*)}$ Colaboraram na execução do projeto em 2014 e na organização do artigo: Cristiana Barcelos da Silva, Pedagogia, Mestra e Doutoranda em Cognição e Linguagem pela Universidade Estadual do Norte Fluminense; e Elizangela Rosa Juvêncio, Pedagogia pelo Centro Universitário São Camilo e Mestranda em Políticas Sociais pela Universidade Estadual do Norte Fluminense.

${ }^{(* *)}$ Gerson T. Carmo. Professor Associado da Universidade Estadual do Norte Fluminense Darcy Ribeiro (UENF). Cursou doutorado em Sociologia Política e mestrado em Cognição e Linguagem, ambos na UENF. Email: gtavares33@gmail.com.
} 
Desse modo, a iniciativa descrita nesse artigo teve como finalidade geral criar ambientes de formação continuada docente, capazes de promover experiências, registros e reflexões sobre memórias orais da EJA, de seu reconhecimento e de visibilidade a partir de narrativas autoras.

Interessante destacar que, do ponto de vista das políticas públicas e sociais, eram quiméricas as ações de EJA e, na universidade em questão, a extensão e a pesquisa não eram pautadas por discussões nessa temática. Por esta razão, o projeto Diagnóstico da EJA, em sua essência territorial, não deixou de ser uma insigne estratégia de empoderamento, no sentido de dar visibilidade à EJA, que historicamente e em algumas práticas discursivas no tempo presente posicionam socialmente a modalidade de maneira secundária e preterível (HADDAD, 2000).

Nesse sentido, o enlace entre UENF e EJA se concretiza na relação entre extensão e pesquisa, sendo esta considerada visceral para manter vivo, e avançando, o processo de descobertas iniciado com o projeto inicial do Diagnóstico da EJA. Notório saber que a proposta de extensão fundamentou-se teoricamente na perspectiva da Teoria do Reconhecimento Social (TRS) de Axel Honneth (2003). Por essa razão, pautados no papel da universidade e em sua relação com a teoria adotada, estabelecemos duas estratégias fundamentais para a ação de formação continuada com os professores de EJA de Itaperuna:

i) a premissa da importância do relacionamento institucional e profissional, com foco no reconhecimento social dos sujeitos professores;

ii) a autoria escrita como princípio ativo de formação continuada entre os docentes partícipes da proposta.

Assim, articulando a TRS com a perspectiva da memória oral, objeto também desse projeto, emergia juntamente a autoria escrita - compreendida como lugar de fronteira entre as experiências e saberes tácitos e a expressividade destes por meio de suas representações e relações com o ato de escrever.

A proposta apresentada envolveu, na UENF, três pesquisadores associados, configurando uma parceria institucional interna necessária para suporte decisório na contrapartida da universidade ao projeto, que teve também a pretensão de se transformar em programa de extensão institucional. Além dos pesquisadores envolvidos no projeto, contamos com o apoio de cinco bolsistas (três de iniciação científica e duas professoras da educação básica), por um ano, em meses alternados, pertencentes ao projeto Diagnóstico da Qualidade do Ensino no PROEJA da região Norte Noroeste Fluminense: aspectos formativos e metodológicos", contemplado com o Edital 49/2012 Capes/Inep/Observatório da Educação, assim como a assessoria do Prof. Osmar Fávero, 
pesquisador da Universidade Federal Fluminense (UFF), especialista em memória da educação popular (EP) e da EJA.

Como a UENF não tinha tradição histórica de atuação na área de EJA, se comparada a outras Instituições de Ensino Superior (IES), apresentaria desvantagem em relação às IES que a detinham. Contudo, na ocasião, a intenção seria a de tornar tal desvantagem, vantajosa, tendo em vista que a expectativa de implantação do projeto pressupunha fomentar demandas gradativas por políticas e ações de EJA, não apenas no entorno da região mais próxima à universidade mas, quem sabe, aos demais municípios do estado. A aspiração a ser perseguida se explica pelo desejo de tornar a EJA e seus atores visíveis do ponto de vista social, político e educacional, assim como frente de discussões e pesquisas acadêmicas na graduação e na pós-graduação (CARMO, 2010).

\section{BASES DA PROPOSTA: QUESTÕES TEÓRICAS, HISTÓRICAS, POLÍTICAS E SOCIAIS PARA FORMULAÇÃO DA FORMAÇÃO CONTINUADA DE DOCENTES DA EJA}

Parece-nos que pensar uma proposta de formação continuada para professores no plano teórico requer refletir sobre algumas questões, especialmente de natureza histórica, política e social. Levar em consideração tópicos específicos como a subjetividade e a superação de problemáticas foram o fermento para a problematização de questões de poder envolvidas na memória seletiva, que despreza de antemão experiências docentes, mesmo diante da possibilidade de causar impacto positivo sobre a permanência de estudantes, conforme levantamento feito junto a 169 alunos de EJA em Itaperuna ${ }^{1}$.

Na contramão dessa desconsideração, o projeto, ao prestigiar as práticas acumuladas no cotidiano dos professores, se propôs a transformar memórias orais em documentos escritos sobre ações docentes realizadas nessa modalidade. Produzir e reproduzir os relatos docentes, além de se atrelar à proposta da TRS, constituiu também um desafio autoral instituinte, no sentido dado por Linhares $^{2}$ (2007).

\footnotetext{
${ }^{1}$ No ano de 2011, foi aplicado um questionário a 169 alunos de EJA matriculados na rede municipal de educação do município de Itaperuna. Nele, entre as questões apresentadas, a que mais "saltou aos olhos" se referiu aos fatores que influenciavam os discentes a permanecerem na instituição. Os dados revelaram que, do total de alunos, $41 \%$ sinalizou que a ação do professor é elemento que mais determina a decisão dos estudantes para permanecerem na escola.

${ }^{2}$ Aqui nos apropriamos do termo utilizado por Célia Linhares (professora titular de Política Educacional da UFF), em suas pesquisas sobre "Experiências Instituintes em Escolas Públicas", que congregam toda uma bibliografia referente às reformas educacionais, inovações e movimentos instituintes na escola, e instrumentos epistemológicos para percebermos outros tipos de relações pedagógicas, ainda embrionárias, que prometem alargar práticas e concepções de conhecimento escolar, em que objeto e sujeito se interpenetram e se conjugam com a vida e a responsabilidade de exercitá-la de forma respeitosa e includente.
} 
Esta possibilidade de vincular a autoria como incentivo no processo de reconhecimento social junto aos sujeitos que se encontram nessa "educação de segunda linha", advém do fato de que Honneth (2003) quando diz que "a tensão afetiva, provocada pelo sentimento de humilhação do indivíduo, só pode ser dissolvida por ele na medida em que reencontra a possibilidade da ação ativa fundada em práticas sociais de reconhecimento". Portanto, na medida em que pesquisadores e professores discursam e escrevem sobre suas práticas carregadas de reconhecimento social no mundo da sala de aula, inscrevem-se numa relação amigável (afetiva) com o ato de escrever, empoderando-se de seus potenciais, de subjetividades, de desafios e, até mesmo, reconhecendo preconceitos instituídos. Assim, pesquisadores e professores descrevem uma outra realidade, não opressiva, mas zelosa, que reinventa uma escrita de suas realidades fora do velho jogo "educação de primeira linha" versus "educação de segunda linha" (HADDAD, 2000).

Pode revelar, pois, ainda, a perspectiva interpretativa pela qual esses sujeitos se inseriram nessa história, ao narrarem o vivido, reconstituindo assim outra história, diversa, complementar e crítica da versão oficial corrente, enriquecendo-a.

No que tange à memória social, em sua forma oral, é conhecida a posição de Benjamin (1975, p. 197) acerca de os seres humanos estarem se privando da "faculdade de intercambiar experiências" porque "as ações da experiência estão em baixa, e tudo indica que continuarão caindo até que seu valor desapareça", devido às rápidas mudanças tecnológicas que fazem com que nada permaneça como era. Mas, exatamente por isso, é que Benjamin faz um campo de interpretação se abrir, quando pensa a memória como depositária de energia capacitante, oriunda de um passado que não foi permitido existir.

Nessa perspectiva, a narrativa é carregada de sabedoria e é uma forma artesanal de comunicação; na narrativa encontra-se sempre a marca do narrador: “[...] imerge essa substância na vida do narrador para, em seguida tirá-lo dele próprio" (BENJAMIN,1975, p. 69).

O que há de mais surpreendente na teoria da história de Benjamin é conceber o passado como algo inacabado, algo que não está fechado, que nas palavras de Bolz (1992, p. 13) assim se traduz: “[...] se a memória vai ao arrepio da história, o passado ainda não está encerrado. Fica em aberto e pode ser usado, portanto, como ponto de referência da utopia. Esta é a reviravolta fundamental para Benjamin”.

A valorização da memória como força emancipatória também pode ser encontrada em Santos (1996, p. 7), quando afirma que "não se pode pensar a transformação e a emancipação social sem reinventar o passado". Por isso, o passado passa a ser visto como um recurso pedagógico, e não 
como um relato, ou seja, pode ser visto como "uma força capaz de irromper em um momento de perigo", transformando atitudes e relações interpessoais e/ou intergrupais.

Conforme Benjamin (1975), a narrativa é comunicação artesanal e encerra em si uma dimensão prática, de um conselho, de um ensinamento moral ou de uma forma de vida. Por isso, uma proposta de produção de documentos escritos com base na memória oral é condizente com o sentido próprio da entrevista não como fonte para um produto posterior e final da pesquisa, mas como "momento fundante onde não só recolhe-se a história, mas onde se vive a memória e cria-se um acontecimento que também faz história” (LE VEN, 1997, p. 221).

Assim, articulando reconhecimento com a perspectiva da memória oral, objeto desse projeto, emerge a questão da autoria, fronteira entre experiências e saberes tácitos e a expressividade destes, por meio das narrativas pessoais registradas em audiovisual, como subsídio à formação continuada de docentes de EJA.

\section{O DESENVOLVIMENTO DA PROPOSTA}

Ao longo de dois anos, várias atividades paralelas foram desenvolvidas na região, em torno da formação continuada no município de Itaperuna, articulando os eixos memória, autoria e permanência escolar. Dentre elas: formação continuada para gestores de EJA em Itaperuna; parceria com a Secretaria de Educação de Campos dos Goytacazes para a realização de mais duas formações com professores de EJA; produção textual e gravação de narrações de memórias; organização de documentação proveniente de quatro cursos de extensão realizados; transcrição de gravações e/ou filmagens realizadas; criação de uma página gratuita na internet para o grupo docente, com inserção de fotos produzidas de forma voluntária. ${ }^{3}$

Para o objetivo deste artigo, o recorte tratado a respeito das temáticas como parte da proposta de formação continuada será ilustrado com depoimentos, fruto das narrativas sobre as relações dos docentes com a escrita.

Foram duas temáticas desenvolvidas nas formações. A primeira, intitulada Do medo de escrever ao direito autoral na EJA objetivou constituir um ambiente de discussão em torno do medo de escrever relatado pelos docentes da rede pública do ensino fundamental de Itaperuna. Sentir-se bem ou ter uma relação amigável com a escrita é exceção; a regra é o medo, o desconforto. Entretanto, indaga-se, na condição impelida de narradoras-autoras, se tais docentes não seriam provocadas em sua necessidade humana de comunicação. E, consequentemente, em seu

\footnotetext{
${ }^{3}$ Material disponível em: <https://plus.google.com/114731546650103954175/posts〉.
} 
desejo e esforço em relação à escrita para produções textuais de própria autoria, necessárias à condição docente, enquanto exemplos de uso escrito da língua materna como processo de emancipação da comunicação humana.

A segunda temática, intitulada Permanência escolar na educação de jovens e adultos: uma escrita nascente a propósito da qualidade do ensino na EJA, considerou que o termo permanência escolar, embora ainda incipiente em relação a publicações sobre a ideia de evasão (CARMO; CARMO, 2014), é cada vez mais referido nas pesquisas sobre a EJA. Dessa maneira, entende-se que a preocupação com o permanecer na escola anuncia mudanças no modo de refletir sobre a evasão e o fracasso escolar de jovens e adultos. Se o senso comum de alunos, professores e gestores atribui ao aluno a responsabilidade pela sua evasão ou fracasso escolar, as crescentes formulações em torno da noção de permanência vão apontar para situações, empíricas ou não, nas quais outros operadores educacionais, além do aluno, assumem coletivamente tal responsabilidade, no desafio da construção coletiva do direito a uma educação de qualidade.

$\mathrm{Na}$ esteira dessas temáticas que pautaram as discussões e atividades de formação de 80 docentes, foi possível observar tomadas de consciência sobre o próprio bloqueio de escrever, bem como a consciência dos usos da escrita que lhes davam prazer, mas que, em maioria, não faziam parte de suas propostas de escrita no cotidiano na sala de aula. A partir desses momentos de tomada de consciência emergiu com facilidade a associação entre o medo de escrever e o sentir-se desconfortável ou envergonhado em sala de aula, comuns entre os estudantes, como sentimentos que representam possíveis fatores de não desejar permanecer na escola.

Para ilustrar tais situações, seguem alguns depoimentos a respeito da relação que professoras cursistas declararam ter com a escrita. O primeiro grupo de depoimentos explicita exemplos de relações positivas com a escrita:

\section{Depoimento 1.Expressa o prazer e a liberdade que sentia ao escrever em seu diário}

A minha relação com a escrita é de muita timidez. Parece que as ideias fugiam, sumiam de repente, pois sempre fui muito tímida e com muita dificuldade de escrever, de criar, de narrar histórias. Lembro-me de ter feito pouca redação na escola, mas escrevia muito no meu querido diário e adorava. Era tudo pra mim, pois eu podia escrever à vontade sem ninguém julgar se estava certo, errado, bobo ou ridículo. Eu colecionava e adorava escrever poesias em papel carta. Lembro que na quinta série a professora pediu para escrever algo que aconteceu sobre mim, mas as ideias não vinham de jeito nenhum, então resolvi escrever a letra de uma música, como se tivesse acontecido comigo e foi muito mais engraçado, nem ela (professora) aguentou! Recordo como se fosse hoje, porém o tempo passa, as coisas mudam e hoje não sou tão tímida 
assim.Tirei uma nota ótima na redação do concurso para o estado, mas, também treinei muiiiito!!! (D. A., 2013).

\section{Depoimento 2. Relata o apoio que sempre recebeu em casa, e o fato de ter sido alfabetizada pelas irmãs que também são professoras}

Venho de uma família que, na maior parte, é composta por professores. Sou a caçula de 11 irmãos, muito bem direcionada pelos meus pais e pelas irmãs professoras. Meus pais estudaram somente até a $3^{\text {a }}$ série do ensino fundamental, mas com muito esforço e dedicação souberam educar e direcionar os filhos. Em minha escolaridade, não frequentei a pré-escola, que é uma etapa de suma importância para o desenvolvimento de uma criança, porém minhas irmãs professoras sempre me deram suporte em casa para o meu desenvolvimento. Tive o ingresso na escola aos sete anos, direto no $2^{\circ}$ ano do fundamental. Fui alfabetizada em casa por uma das minhas irmãs. Sempre gostei muito de brincar de dar aulas para as minhas bonecas, acho porque sempre vivi essa realidade em meu cotidiano de vida. Gostava muito de ouvir e contar histórias, escrever cartinhas e bilhetes. Apesar de ter sido muito motivada na área da aprendizagem, hoje não sei explicar o porqu, me sinto um pouco travada na escrita (B. A., 2013).

\section{Depoimento 3. A valorização da escrita do aluno, pelo professor - reflexos permanentes}

Em todo o percurso da minha vida sempre valorizei a escrita em diversos contextos e acredito que isso se deve ao ambiente em que fui criada por minha mãe. Ela sempre lia e cantava para mim e meus irmãos, e nos estimulava a responder questões a nós direcionadas. Na escola sempre gostei muito de escrever e falar. Até hoje, quando começo a escrever, escrevo além do esperado, pois as ideias fluem com mais facilidade. Tenho muitas lembranças de uma professora que valorizava a minha escrita, sempre comentava o que eu escrevia, e achava o máximo eu escrever muito. Gosto de usar palavras novas e sempre recorro ao dicionário quando tenho necessidade. Meu desejo é passar esse gosto pela escrita para minhas filhas e alunos, penso muito em formas de estimular as pessoas que conheço para esta prática (N. A., 2013).

Como é possível observar, o reconhecimento social está presente na relação com a escrita. Pessoas que influenciam e fazem parte das lembranças positivas que essas três professoras têm ao escrever. As memórias ditas e escritas entre as colegas se propagavam gerando expectativa e curiosidade, como se estas fossem felizardas, haja vista que apenas 35\% das 40 depoentes declararam sempre ter tido relações positivas com a escrita.

No segundo grupo de depoimentos é possível observar o contrário. São três declarações de diferentes receios e bloqueios com a escrita que representam a maioria das cursistas. 


\section{Depoimento 4. A limitação da cartilha de alfabetização como único material didático}

Como moradora na zona rural e de família com dificuldades financeiras, fui para a escola com sete anos. Nessa época, a alfabetização se dava a partir do ingresso na escola. Fui alfabetizada pelo método da "Cartilha da Infância". E, por não ter contato com outros materiais didáticos, apresentei lentidão nos primeiros anos de escolaridade. Minha leitura e compreensão de texto eram precárias. E isso se arrastou por todo o fundamental e parte do ginásio. No normal tive muita dificuldade em fazer sínteses e não empregava de forma correta as regras gramaticais. Mesmo assim, fui aprovada, tendo sempre médias regulares. Com essa herança, passar nos concursos era um desafio. Mesmo assim, consegui a duras penas. Percebi que parte dessa minha dificuldade começou a ser vencida depois que comecei a trabalhar como professora das séries iniciais. Ainda me sinto escrava dessa falta de cultura, mas faço o possível e o impossível para ser melhor a cada dia. (A. A., 2013).

\section{Depoimento 5. A dificuldade de transpor para o papel o que se pensa}

Não me recordo muito, mas iniciei minha escrita nas séries iniciais fazendo cópias no caderno de pauta dupla. Com o passar do tempo fui entendendo que o que fosse que escrevesse teria que ser de forma correta, pois quem fosse ler compreenderia o que estava querendo dizer. Transpor para o papel o que pensamos ou algo que nos seja sugerido para escrever não é uma tarefa muito fácil, pelo menos para mim. Sempre tive e ainda tenho uma dificuldade muito grande em iniciar qualquer coisa que tenho que relatar, falar ou até mesmo o que penso. Tenho consciência que preciso ler muito mais, pois assim minha dificuldade irá aos poucos amenizando. Para eu escrever e ser compreendida é um grande desafio. Espero chegar ao final deste curso, não totalmente, mas bem menos insegura em relação a qualquer coisa que tenha que escrever. Escrever para mim é uma arte que poucas pessoas dominam, mas a cada dia que passa me esforço para que um dia me sinta segura e sem medo de escrever (B. Z., 2013).

\section{Depoimento 6. A vergonha de assinar o nome diante das pessoas}

O meu contato com a escola foi aos sete anos, gostava muito de estudar, porém não era fã de leitura. Estudei em escola pública e não tive dificuldade de aprender. Na adolescência, gostava muito de escrever histórias que inventava, porém a minha escrita não era bonita. Certo dia, quando estava no ensino médio, uma professora mandou cada aluno em sua mesa para assinar o nome. Ao assinar o meu nome essa professora me fez passar vergonha, dizendo que além de ter demorado a escrever, a minha letra era horrível. Levei muitos anos com vergonha de assinar o meu nome na frente das pessoas; até hoje tenho receio de escrever e tenho dificuldade de me expressar quando apresento algum trabalho, mesmo que eu tenha domínio da matéria, fico nervosa e não consigo passar tudo que entendi (N. A., 2013). 


\section{CONTEXTOS E REFLEXÕES SOBRE OS RESULTADOS OBTIDOS}

O fortalecimento e a importância do diálogo coletivo nas ações realizadas na proposta de formação continuada para professores giraram em torno de três principais processos:

1) diálogo instrumental na construção e aplicação de instrumentos de coleta e de interpretação de dados;

2) relacionamento institucional e profissional, com foco na valorização e reconhecimento social dos protagonistas-professores da EJA;

3) autoria e memória (ideias/produção textual) como princípio ativo de formação continuada entre os participantes do projeto, visando a práticas pedagógicas mais consequentes, que garantissem a permanência dos estudantes no processo educacional.

Importante ressaltar que tal formulação reflexiva sobre o caráter dialógico, relacional e autoral do projeto só foi possível após um acúmulo representativo de experiências inéditas, porque orientadas de forma assistemática pelo conceito de reconhecimento social. Constituíram, assim, um corpus empírico de dados, do qual emergiu uma expectativa político-pedagógica coletiva em torno de uma investigação sustentada na autoria e na memória de professores de EJA.

Tanto na Teoria do Reconhecimento Social quanto na noção de autoria e memória na EJA, percebeu-se uma movimentação "tática", , subliminar, no compromisso institucional estabelecido, a partir de uma expectativa criadora e de formas renovadas de relacionamento, fundadas no tripé pesquisa-ensino-extensão, principalmente, quanto à atuação desses professores em cidades pequenas". Tal "tática" tornou-se uma "estratégia" metodológica explícita, haja vista a emersão das dimensões dialógica, relacional e autoral que permitiram conduzir de modo holístico e estruturante as reflexões sobre as ações do projeto de formação continuada.

No que diz respeito ao aspecto da autoria como princípio ativo da proposta de formação continuada para docentes, cujo pressuposto é enfatizar a dimensão criativa e subjetiva no processo

\footnotetext{
${ }^{4}$ Michel de Certeau (1990, p. 100) define "tática" como "[...] a ação calculada que é determinada pela ausência de um próprio. Então nenhuma delimitação de fora lhe fornece a condição de autonomia. A tática não tem por lugar senão o do outro. E por isso deve jogar com o terreno que lhe é imposto tal como o organiza a lei de uma força estranha".

${ }^{5}$ Conforme o IBGE, no ano 2000, 55\% dos 92 municípios do estado do Rio de Janeiro tinham menos de 30 mil habitantes. Entre os poucos trabalhos que estudam a cidade pequena no Brasil, pode-se citar Cidade pequena: paraíso $e$ inferno da pessoalidade (PRADO, 1997).

${ }^{6} \mathrm{Na}$ visão de Michel de Certeau (1990, p. 99) "estratégia" refere-se a uma ação que supõe a existência de um lugar próprio, "como algo próprio e ser a base de onde se podem gerir as relações com uma exterioridade".
} 
de ensino-aprendizagem da e pela memória da EJA, ressalta-se a consequente visibilidade ao estatuto cognoscitivo dado à experiência humana.

Os resultados obtidos permitiram integrar uma dimensão epistemológica às dimensões dialógica, relacional e autoral das memórias praticadas ao longo da proposta, especificamente no estudo sobre a permanência na EJA, que subverte a ordem naturalizada da maioria dos estudos sobre evasão, que a justificam pelo viés da carência cultural, ou da deficiência alimentar, ou da necessidade de trabalho, ou da falta de interesse, ou por combinações entre estas e outras causas desqualificadoras dos sujeitos da EJA.

O processo desenvolvido permitiu dizer aos docentes que os fatores que influenciam o estudante a resistir para permanecer têm a ver com a ação de reconhecimento de que tal estratégia (resistir e permanecer) tem duas frentes: a) uma, diretamente, ligada aos docentes de EJA que permanecem na modalidade, conscientes de seu compromisso em sala de aula, produzindo êxito; e b) outra, indiretamente, junto àqueles discentes de EJA, cuja "ilusão fecunda", os faz retornar à escola e nela resistir para permanecer, em especial aqueles que ainda não dominam a leitura e a escrita para os usos no cotidiano. Ao (re)construir, pela formação continuada, memórias de práticas pedagógicas de professores, se fortalece a mobilização em prol da modalidade EJA, atuando como parte da luta pelo direito a uma educação pública e de qualidade.

\section{REFERÊNCIAS}

BENJAMIN, Walter. A modernidade e os modernos. Rio de Janeiro: Tempo Brasileiro, 1975.

BOLZ, N. W.; KONDER, Leandro. É preciso teologia para pensar o fim da história? Revista USP. São Paulo, n. 15, set.-nov. 1992. Disp.: 〈http://www.usp.br/revistausp/n15/fbolztexto.html>. Acesso: 1 dez. 2014.

CARMO, Gerson Tavares. O enigma da educação de jovens e adultos: um estudo das evasões e retornos à escola sob a perspectiva da Teoria do Reconhecimento Social. 2010. 332f. Tese (Doutorado em Sociologia Política) - Universidade Estadual do Norte Fluminense Darcy Ribeiro, Campos dos Goytacazes, 2010.

; CARMO, Cíntia T. A permanência escolar na Educação de Jovens e Adultos: proposta de categorização discursiva a partir das pesquisas de 1998 a 2012 no Brasil. Education Policy Analysis Archives, v. 22, n. 63 , 2014. Dossiê Educação de Jovens e Adultos II. Editoras convidadas: Sandra Regina Sales e Jane Paiva, v. 22, p.1-45, 2014.

CERTEAU, Michel de. A invenção do cotidiano. 1. Artes de fazer. 3. ed. Petrópolis: Vozes, 1990.

HADDAD, Sérgio. (Coord.). O Estado da Arte das Pesquisas em Educação de Jovens e Adultos no Brasil: a Produção Discente da Pós-Graduação em Educação no Período 1986 - 1998. São Paulo: Ação Educativa, 2000.

HONNETH, Axel. Luta por reconhecimento: a gramática moral dos conflitos sociais. São Paulo: Ed. 34, 2003.

LE VEN, M.; FARIA, E.; MOTTA, M. H. Sá. História de vida: o instante da entrevista. In: SINSOM, O. R. M. V. (Org.). Os desafios contemporâneos da História Oral. Campinas: CMU - Publicações/Unicamp, 1997. p. $217-221$.

\footnotetext{
${ }^{7}$ Ilusão fecunda é uma expressão utilizada na obra de Sposito (1993), que trata dos movimentos de imigrantes em São Paulo, na luta por educação na década de 1970. Ressalta que o desejo de busca dos alunos pela escola irá ajudá-los a obter os conhecimentos necessários para uma vida melhor e socialmente mais valorizada.
} 
LINHARES, Célia. Experiências instituintes na educação pública? Alguns porquês dessa busca. Revista de Educação Pública. Cuiabá, v. 6, n. 31, p. 139-160, maio-ago. 2007.

PAIVA, Jane. Os sentidos da educação para jovens e adultos. Rio de Janeiro: DP et Alii/Faperj, 2009.

Projeto Centro de Referência e Memória da Educação de Jovens e Adultos no Rio de Janeiro. Rio de Janeiro: UERJ, Documento elaborado para submissão a agências estaduais e federais de fomento à pesquisa, 2012. (mimeo.)

PRADO, R. M. Cidade Pequena: paraíso e inferno da pessoalidade. Cadernos de Antropologia e Imagem. Rio de Janeiro, v. 4, n. 1, p. 31-56, jan./jun. 1997.

SANTOS, Boaventura de Sousa. Pela mão de Alice: o social e o político na pós-modernidade. Lisboa: Leya, 1996.

SPOSITO, Marília Pontes. A ilusão fecunda. São Paulo: Hucitec, 1993.

\section{RESUMO}

O presente trabalho refere-se a uma ação de formação continuada para professores da educação de jovens e adultos (EJA) realizada no biênio de 2013 a 2014 na cidade de Itaperuna, localizada na região Noroeste Fluminense do estado do Rio de Janeiro. Idealizada pela Universidade Estadual do Norte Fluminense Darcy Ribeiro (UENF), a partir de resultados sobre a permanência escolar na região mencionada, que apontam ser o professor aquele que mais influencia na permanência dos estudantes. O projeto de extensão e pesquisa teve como horizonte o reconhecimento social docente por meio de suas memórias pedagógicas, entendidas como matéria prima para a elaboração de narrativas de experiências que deram certo, sob o ponto de vista autoral. Dessa forma, articularam-se as experiências que afetaram os professores, marcadas em suas memórias, como meio de valorização subjetiva, a fim de desenvolver ações conexas à qualidade de suas atuações na EJA, apontando para o protagonismo dos atores educacionais envolvidos no processo de ensinoaprendizagem. Como desdobramentos dos encontros de formação realizados foi criado um grupo de discussão permanente composto por docentes de EJA, o que nos fez inferir o realce do papel e da responsabilidade da UENF ao inaugurar um campo de extensão e pesquisa nesta modalidade de educação.

Palavras-chave: Formação Continuada; Educação de Jovens e Adultos; Permanência Escolar.

\section{SCHOOL PERSISTENCE, MEMORY AND AUTHORSHIP: A PROPOSAL OF CONTINUING TRAINING FOR YOUTH AND ADULT EDUCATION TEACHERS AT THE UENF}

\section{ABSTRACT}

This work discusses the continuing training for Youth and Adult Education (EJA, in Portuguese) teachers in the city of Itaperuna located in the Nortwestern Region of the State of Rio de Janeiro from 2013 to 2014. The research was conducted at the Universidade Estadual do Norte Fluminense Darcy Ribeiro (UENF) from findings of school persistence in the area showing that the teacher is the one with more influence on the students' school persistence. The extension project aimed at the teachers' social acknowledgment through their pedagogical memories seen as sources for the elaboration of narratives of successful experiences in the authors' viewpoint. Therefore, the experiences which affected the teachers, marked in their memories. were articulated as a means of subjective valuation to develop actions linked to the quality of their performance in EJA, evidencing the educational actors' protagonism in the teaching-learning process. Following the training meetings, a permanect discussion group was created comprising EJA teachers and emphasizing the UENF's role and responsibility for the opening of an extension campus for this modality of education.

Keywords: Continuing Training; Youth and Adult Education; School Persistence.

Submetido em Jan. 2016

Aprovado em Jun. 2016 